\title{
Procalcitonin and C-reactive protein levels in HIV-positive subjects with tuberculosis and pneumonia
}

\author{
G.K. Schleicher*, V. Herbert*, A. Brink", S. Martin\#, R. Maraj", \\ J.S. Galpin and C. Feldman*
}

ABSTRACT: Pulmonary tuberculosis (PTB) and pneumococcal community-acquired pneumonia (PCAP) are common causes of lower respiratory tract infections in HIV-seropositive patients and may have similar clinical and radiological features. This study aimed to assess the value of serum procalcitonin (PCT) and C-reactive protein (CRP) levels in HIV-seropositive patients with pneumonia, and to investigate their potential role in differentiating pneumococcal from mycobacterial infections.

HIV-seropositive patients admitted with pneumonia were evaluated prospectively, 34 with PTB and 33 with PCAP.

All 33 patients in the PCAP group and 20 of 34 patients in the PTB group had elevated PCT levels $\left(>0.1 \mathrm{ng} \cdot \mathrm{mL}^{-1}\right)$. All patients in both groups had elevated CRP levels $\left(>10 \mathrm{mg} \cdot \mathrm{L}^{-1}\right)$. The PTB group had significantly lower CD4 T-lymphocyte counts, lower CRP levels, lower white cell counts, and lower PCT levels than the PCAP group. Receiver operating characteristic analysis showed that optimal discrimination between PTB and PCAP could be performed at a cut-off point of $3 \mathrm{ng} \cdot \mathrm{mL}^{-1}$ for PCT (sensitivity $81.8 \%$; specificity $82.35 \%$ ) and $246 \mathrm{mg} \cdot \mathrm{L}^{-1}$ for CRP (sensitivity

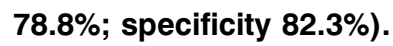

In conclusion, HIV-seropositive patients with pneumococcal community-acquired pneumonia had significantly higher procalcitonin and $\mathrm{C}$-reactive protein levels than those with pulmonary tuberculosis. A procalcitonin level $>3 \mathrm{ng} \cdot \mathrm{mL}^{-1}$ and a C-reactive protein level $>246 \mathrm{mg} \cdot \mathrm{L}^{-1}$ were both highly predictive of pneumococcal infection.

\section{KEYWORDS: C-reactive protein, HIV, pneumococcal pneumonia, procalcitonin, tuberculosis}

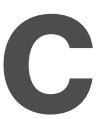
ommunity-acquired pneumonia (CAP) is a common cause of disease and hospital admission among HIV-seropositive patients living in sub-Saharan Africa. Streptococcus pneumoniae and Mycobacterium tuberculosis are two of the most frequent bacterial causes of CAP in this population and may have similar clinical presentations [1]. In addition, HIV co-infection often alters the radiographic presentation of pulmonary tuberculosis (PTB), such that there is a higher prevalence of lobar and lower zone consolidation, making it even more difficult to distinguish these infections from other common bacterial causes of pneumonia [2]. Thus, patients admitted to hospital with CAP are frequently treated empirically for multiple organisms, whilst awaiting results of investigations. This approach is costly, exposes patients to potentially harmful chemotherapy and may lead to inappropriate therapy that negatively influences morbidity and mortality.
C-reactive protein (CRP) is an acute-phase protein and a nonspecific marker of systemic inflammation. In HIV-seropositive patients it is increased in both pneumococcal CAP (PCAP) [3] and PTB [4]. Procalcitonin (PCT) is a 116 amino acid protein with a sequence identical to that of the pro-hormone calcitonin. It is synthesised by leukocytes and is found in elevated concentrations in the blood in bacterial infections and the inflammatory response syndrome. Elevated PCT levels are thought to be a specific marker of bacterial sepsis in HIV-seropositive patients [5], and high levels have been described in patients with bacteraemic PCAP [6]. In contrast to CRP, PCT does not appear to be significantly elevated in patients with PTB $[7,8]$, making it an attractive potentialy rapid diagnostic tool to differentiate bacterial from mycobacterial causes of CAP. However, the value of PCT has not been well studied in the sub-Saharan HIV-seropositive

\section{AFFILIATIONS}

*Dept of Medicine, Johannesburg Hospital and University of the Witwatersrand, \#AMPATH, and

"School of Statistics and Actuarial Science, University of the

Witwatersrand, Johannesburg, South Africa.

\section{CORRESPONDENCE}

G.K. Schleicher

P0 Box 98818

Sloane Park

2152

South Africa

Fax: 27114825984

E-mail: schleicher@worldonline.

co.za

Received:

June 082004

Accepted after revision:

December 202004 
population where there is also a high prevalence of mycobacterial infection. Therefore, the aim of the present study was to investigate the diagnostic value of admission serum PCT levels in differentiating PCAP from PTB in adult HIV-seropositive patients in an area of high tuberculosis prevalence.

\section{PATIENTS AND METHODS Study design and subjects}

This was an open, prospective, observational study of consecutive HIV-seropositive patients with CAP admitted to the Johannesburg Hospital, Johannesburg, South Africa, between January 2001-October 2003. The study was approved by the University of the Witwatersrand Human Research Ethics Committee, Johannesburg, South Africa. Medical and written consent was obtained from all subjects. All subjects received counselling pre- and post-HIV testing. Of the 88 screened patients, 67 met the inclusion criteria and were classified into the PTB group or PCAP group. None of the patients in this study were receiving, or had previously received, antiretroviral therapy. Subjects were considered to have PTB if they had new infiltrates on the chest radiograph and a positive acid-fast bacilli smear on routine Ziehl-Neelsen staining of sputum or bronchial washings, or histological evidence of mycobacterial infection on a lung tissue biopsy specimen, together with a positive Mycobacterium tuberculosis culture of the specimen. Subjects were considered to have PCAP if they had clinical signs of pneumonia (fever $>38^{\circ} \mathrm{C}$ or $<36^{\circ} \mathrm{C}$, cough productive of purulent sputum, crackles on auscultation of the chest, pleuritic chest pain, tachypnoea, or tachycardia), leukocytosis $\left(>10 \times 10^{9} \mathrm{cells} \cdot \mathrm{L}^{-1}\right)$ or leukopenia $\left(<4 \times 10^{9}\right.$ cells $\left.\cdot \mathrm{L}^{-1}\right)$, and a new infiltrate on the chest radiograph. The aetiological agent was considered to be Streptococcus pneumoniae if the patient had a positive blood culture for $S$. pneumoniae, there was a positive culture of $S$. pneumoniae in a good quality specimen of sputum $\left(>10^{5} \mathrm{cfu} \cdot \mathrm{mL}^{-1}\right)$, or a positive $S$. pneumoniae urinary antigen test (BINAX NOW ${ }^{\mathrm{TM}}$; Portland, ME, USA).

The following parameters were recorded for all patients on admission: demographic data, white blood cell (WBC) count, CD4 T-lymphocyte subset count, CRP, PCT, chest radiographic appearance, and the Acute Physiology and Chronic Health Score (APACHE) II score [9].

\section{Methods}

Serum (5-10 mL) was collected from each patient. Plasma was separated, divided and frozen $\left(\right.$ at $\left.-70^{\circ} \mathrm{C}\right)$ until analysis was performed. PCT values were determined by a monoclonal immunoluminometric assay (LUMItest PCT; BRAHMS Diagnostica, Berlin, Germany), without knowledge of the patients' clinical data. The test took $2-3 \mathrm{~h}$ to perform and required $20 \mu \mathrm{L}$ of serum or plasma. The interassay precision was $6-10 \%$ in the clinically relevant measurement range and analytical assay sensitivity was $0.1 \mathrm{ng} \cdot \mathrm{mL}^{-1}$. The functional assay sensitivity, or the smallest value that can be defined with an interassay precision rate of $20 \%$, was $0.3 \mathrm{ng} \cdot \mathrm{mL}^{-1}$. According to standard procedures, CRP levels were measured by nephelometry (Dade Behring, Marburg, Germany), WBC and differential cell counts by flow cytometry (Beckman Coulter MAX-M, Beckman, USA). CD4 T-lymphocyte subsets were determined by dual-color flow cytometry (Simultest reagents; Becton Dickinson, Brea, CA, USA).

\section{Statistics}

Differences between the two groups were tested using the nonparametric Mann-Whitney U-test for continuous variables, as several variables were skewed. A Chi-squared contingency table test was used for categorical variables. Correlation coefficients were obtained using the Spearman rank correlation coefficient. Optimal cut-offs for prediction of PTB/PCAP grouping were investigated using receiver-operating characteristics (ROC) analysis.

\section{RESULTS}

Of the 67 patients who met the inclusion criteria, 34 had PTB and 33 had PCAP. Of the 33 patients in the PCAP group, three had a positive sputum culture for $S$. pneumoniae, 18 had a positive urinary antigen test, 12 had a positive blood culture for $S$. pneumoniae, one had a positive sputum culture and a positive urinary antigen test, and four patients had a positive blood culture and a positive urinary antigen test. There was no significant difference in the proportion of males and females in the two groups $(p=0.72)$. There was also no significant difference between the groups in terms of the severity of consolidation on the chest radiograph, as determined by the number of lobes involved.

The hospital mortality was $5.8 \%(2 / 34)$ in the PTB group and $3 \%(1 / 33)$ in the PCAP group $(p=0.573)$. This difference was not significant and there was no significant association between mortality and PCT or CRP levels. One patient with PCAP died 5 days after admission from severe sepsis and multi-organ failure. One patient with PTB died 3 days after admission from progressive respiratory failure, and the other died suddenly 7 days after admission from a massive pulmonary embolus, confirmed on autopsy.

The two groups of patients were well matched for age and APACHE II scores (table 1). All 33 patients (100\%) in the PCAP group and 20 of 34 patients $(59 \%)$ in the PTB group had elevated PCT levels $\left(>0.1 \mathrm{ng} \cdot \mathrm{mL}^{-1}\right)$. All patients in both groups had elevated CRP levels $\left(>10 \mathrm{mg} \cdot \mathrm{L}^{-1}\right)$. The PTB group had significantly lower CRP levels, PCT levels and total WBC counts on admission compared with the PCAP group (all $\mathrm{p}<0.0005$; table 1; figs 1 and 2). ROC curve analysis revealed that optimal discrimination between PTB and PCAP could be performed at a cut-off point of $3 \mathrm{ng} \cdot \mathrm{mL}^{-1}$ for PCT (area under the curve 0.8694 ; sensitivity $81.8 \%$; specificity $82.35 \%$ ) and $246 \mathrm{mg} \cdot \mathrm{L}^{-1}$ for CRP (area under the curve 0.8654; sensitivity $78.8 \%$; specificity $82.3 \%$; fig. 3 ).

The PTB group had a significantly lower CD4 T-lymphocyte count than the PCAP group $(\mathrm{p}=0.0074$; table 1$)$, with a significant positive correlation between $\mathrm{WBC}$ and CD4 Tlymphocyte count $(\mathrm{r}=0.3554 ; \mathrm{p}=0.03)$. There was a significant negative correlation between the WBC and the APACHE II score in the PCAP group $(r=-0.369 ; \mathrm{p}=0.03)$, but not in the PTB group. There was a significant negative correlation between the CD4 T-lymphocyte count and the APACHE II score in both the PTB group $(\mathrm{r}=-0.4405 ; \mathrm{p}=0.009)$ and the PCAP group $(r=-0.3746 ; p=0.032)$. There was a strong negative correlation between CD4 T-lymphocyte count and PCT levels in the PTB 


\begin{tabular}{|c|c|c|c|}
\hline & PTB group & PCAP group & $\begin{array}{l}\text { Significance } \\
\text { (p-value) }\end{array}$ \\
\hline Subjects n & 34 & 33 & \\
\hline Sex males:females & $15: 19$ & $17: 16$ & 0.7200 \\
\hline Age yrs & 33.5 (13.25) & $32(10.5)$ & 0.2772 \\
\hline Duration of symptoms days & $30(46)$ & $5(1)$ & $<0.0005$ \\
\hline APACHE II score & $11(4.5)$ & $13(7)$ & 0.1607 \\
\hline PCT $\mathbf{n g} \cdot \mathrm{mL}^{-1}$ & $1.03(3.16)$ & $19.05(43.31)$ & $<0.0005$ \\
\hline CRP $\mathrm{mg} \cdot \mathrm{L}^{-1}$ & $177(101)$ & $341(153.5)$ & $<0.0005$ \\
\hline WBC $\times 10^{9}$ cells $\cdot L^{-1}$ & $6.65(2.78)$ & $14.9(8.35)$ & $<0.0005$ \\
\hline $\begin{array}{l}\text { CD4 T-lymphocyte } \\
\times 10^{6} \text { cells } \cdot \mathrm{L}^{-1}\end{array}$ & $107(157.5)$ & $208(288)$ & 0.0074 \\
\hline
\end{tabular}

Data are presented as median (interquartile range), unless otherwise stated. PTB: pulmonary tuberculosis; PCAP: pulmonary community-acquired pneumonia; APACHE: Acute Physiology and Chronic Health Scores; PCT: procalcitonin; CRP: C-reactive protein; WBC: white blood cells. Interquartile range $=75$ th percentile-25th percentile.

group $(\mathrm{r}=-0.5024 ; \mathrm{p}=0.009)$, but this was not observed in the PCAP group. The PCAP group, but not the PTB group, showed a significant positive correlation between PCT and CRP levels $(\mathrm{r}=0.4154 ; \mathrm{p}=0.016)$. Only the PCAP group showed a significant positive correlation between the APACHE II score and the PCT level $(\mathrm{r}=0.6461 ; \mathrm{p}=0.000)$. In the PCAP group, the CRP and PCT levels were significantly lower in the patients with a positive sputum culture compared with patients with a positive blood culture ( $p=0.02$ for both), but this was not found when the patients with a positive urinary antigen test were compared with patients with a positive blood culture.

\section{DISCUSSION}

The twin epidemics of HIV and tuberculosis (TB) place enormous strain on the limited healthcare resources in subSaharan Africa. A common clinical problem is the differentiation of bacterial TB from TB infection in HIV-seropositive patients presenting with CAP. PCT and CRP levels have been

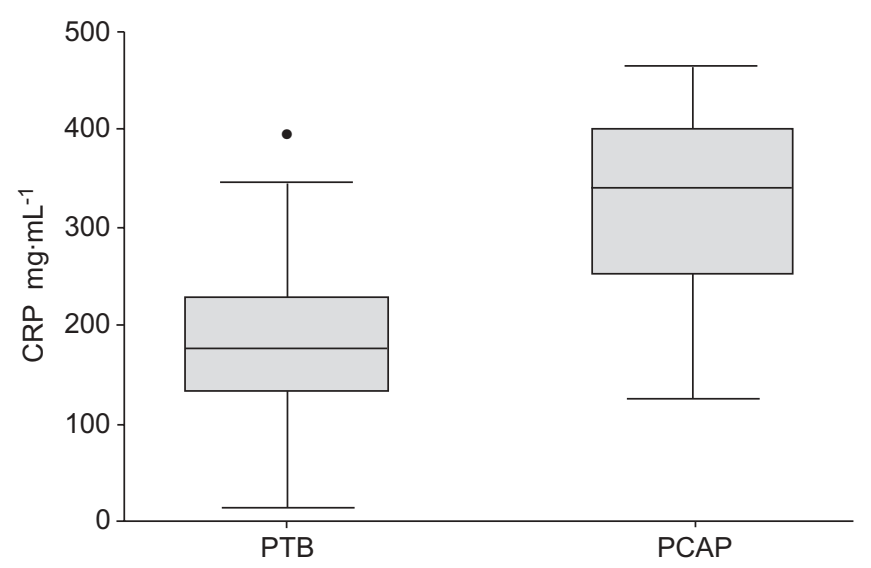

FIGURE 1. Box-and-whisker graph of C-reactive protein (CRP) levels in patients with pulmonary tuberculosis (PTB) and pneumococcal communityacquired pneumonia (PCAP).

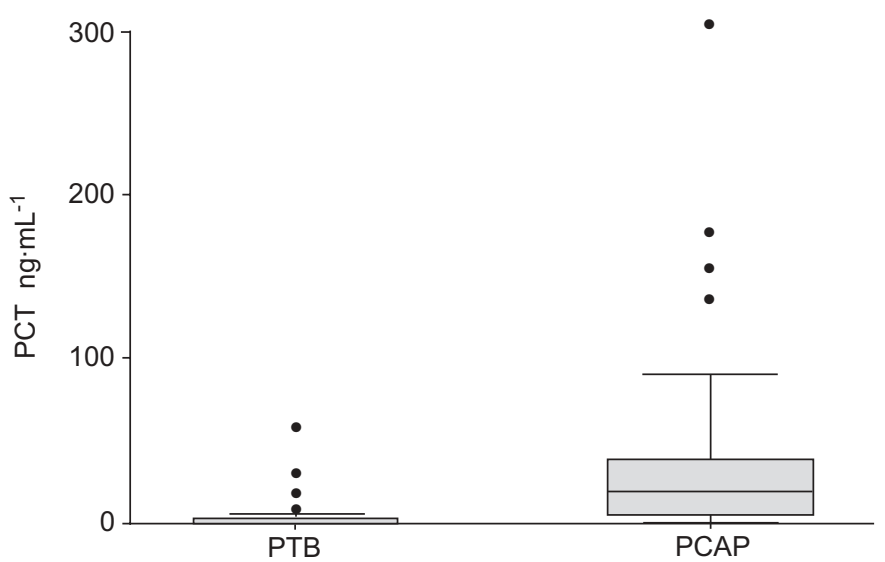

FIGURE 2. Box-and-whisker graph of procalcitonin (PCT) levels in patients with pulmonary tuberculosis (PTB) and pneumococcal community-acquired pneumonia (PCAP).

studied as markers of bacterial lower respiratory tract infection in a number of populations, but results have so far been inconsistent [10, 11]. However, elevated PCT levels in particular have shown good sensitivity for distinguishing invasive pneumococcal infections from viral infections in patients with CAP [6] and for assessing the severity of the disease as measured by the APACHE II score [12]. This is the first study, to the authors knowledge, to determine the value of CRP and PCT in differentiating pneumococcal TB from tuberculous CAP in HIV-seropositive subjects admitted with CAP.

The results of the current study show that both PCT and CRP show good sensitivity and specificity for distinguishing PCAP from PTB in HIV-seropositive patients, with PCT having a better sensitivity $(81.8 \%$ for PCT using a cut-off value of $3 \mathrm{ng} \cdot \mathrm{mL}^{-1}$, compared with $78.8 \%$ for CRP using a cut-off value of $\left.246 \mathrm{mg} \cdot \mathrm{L}^{-1}\right)$. As observed by others $[12,13]$, the PCT level was a useful marker of severity of disease in the PCAP group, but was less helpful in the PTB group. The striking differences in total WBC counts on admission may be the result of the

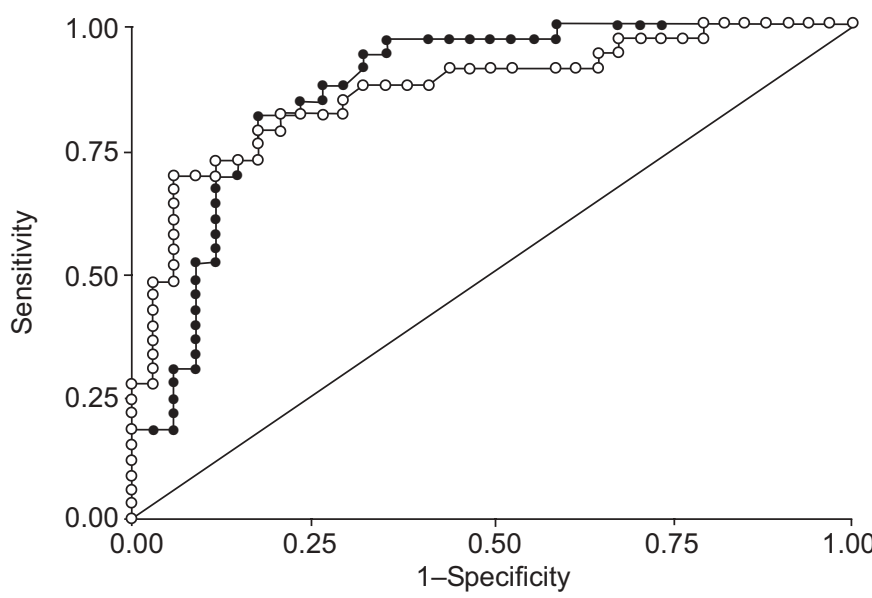

FIGURE 3. Receiver-operating characteristics curve for discrimination between pulmonary tuberculosis and pneumococcal community-acquired pneumonia for procalcitonin $(\bullet)$ and C-reactive protein $(\bigcirc)$. — : reference line. 
more severe immunosuppression and CD4 T-cell lymphopenia in the PTB group. It would be interesting to see if these differences in WBC would be present in patients with PTB and less advanced HIV infection.

In contrast to several published studies $[5,7,8]$, the current study found elevated PCT levels in a significant proportion of patients in the PTB group (59\%). There are several possible explanations for this unexpected finding. First, the majority of the PTB patients in this study had advanced HIV infection with defining features of AIDS and may have had unrecognised, disseminated, bacteraemic TB [14]. Results from the present study show a significant negative correlation between the CD4 T-lymphocyte count and the APACHE II score in the PTB group, indicating increasing severity of disease with worsening immunodeficiency. As suggested by LAWN et al. [7], patients who are severely debilitated or immunosuppressed with extensive or disseminated TB may have elevated PCT levels. Although the two groups had a similar severity of illness, as measured by the APACHE II scores, patients with disseminated TB pneumonia may have a higher mortality than patients with non-TB pneumonia [15]. This suggests that the APACHE II score may underestimate the true severity of illness in these patients. This study did not confirm a significantly higher in-hospital mortality in the PTB group; however, long-term follow-up was not performed. Secondly, both HIV and TB are associated with elevated circulating levels of inflammatory cytokines, particularly tumour necrosis factor- $\alpha[16,17]$. This cytokine has been shown to induce the production of PCT independent of the presence of bacterial endotoxins [18], and may account for the elevated PCT levels found in conditions other than bacterial sepsis, such as malaria [19] and systemic fungal infections [20]. Finally, mixed pulmonary infections with multiple pathogens are not uncommon in HIV-seropositive patients [21, 22] and the elevated PCT levels observed may have been related to undiagnosed and concomitant bacterial infection.

\section{Conclusion}

HIV-seropositive patients with pulmonary communityacquired pneumonia have significantly higher procalcitonin and C-reactive protein levels than those with pulmonary tuberculosis despite similar clinical and radiological appearances. A procalcitonin level $>3 \mathrm{ng} \cdot \mathrm{mL}^{-1}$ and a C-reactive protein level $>246 \mathrm{mg} \cdot \mathrm{L}^{-1}$ are both highly predictive of pneumococcal infection and may lead to an earlier correct diagnosis, more cost-effective investigations, and less exposure to unnecessary antibiotics [23]. However, elevated procalcitonin levels are also found in a significant proportion of HIVseropositive patients with pulmonary tuberculosis, and may be a marker of severe and disseminated tuberculosis or concomitant infection with other bacterial pathogens. Thus, HIVseropositive patients with community-acquired pneumonia and a normal procalcitonin level have a low probability of bacterial pneumonia and pulmonary tuberculosis should be actively ruled out.

\section{ACKNOWLEDGEMENTS}

The authors would like to thank BRAHMS (Hennigsdorf, Germany) and Humor Diagnostica (Pretoria, South Africa) for providing PCT-assay material for this investigator-initiated project.

\section{REFERENCES}

1 Scott JA, Hall AJ, Muyondi C, et al. Aetiology, outcome, and risk factors for mortality among adults with acute pneumonia in Kenya. Lancet 2000; 355: 1225-1230.

2 Post FA, Wood R, Pillay GP. Pulmonary tuberculosis in HIV infection: radiographic appearance is related to CD4 T-lymphocyte count. Tuberc Lung Dis 1995; 76: 518-521.

3 Lala SG, Madhi SA, Pettifor JM. The discriminative value of C-reactive protein levels in distinguishing between community-acquired bacteraemic and respiratory virusassociated lower respiratory tract infections in HIV-1infected and -uninfected children. Ann Trop Paediatr 2002; 22: 271-279.

4 Lawn SD, Wiktor S, Coulibaly D, Ackah AN, Lal RB. Serum C-reactive protein and detection of tuberculosis in persons co-infected with the human immunodeficiency virus. Trans $R$ Soc Trop Med Hyg 2001; 95: 41-42.

5 Gerard Y, Hober D, Assicot M, et al. Procalcitonin as a marker of bacterial sepsis in patients infected with HIV-1. J Infect 1997; 35: 41-46.

6 Moulin F, Raymond J, Lorrot M, et al. Procalcitonin in children admitted to hospital with community acquired pneumonia. Arch Dis Child 2001; 84: 332-336.

7 Lawn SD, Obeng J, Acheampong JW, Griffin GE. Serum procalcitonin concentrations in patients with pulmonary tuberculosis. Trans $R$ Soc Trop Med Hyg 1998; 92: 540541.

8 Polzin A, Pletz M, Erbes R, et al. Procalcitonin as a diagnostic tool in lower respiratory tract infections and tuberculosis. Eur Respir J 2003; 21: 939-943.

9 Knaus WA, Draper EA, Wagner DP, Zimmerman JE. APACHE II: a severity of disease classification system. Crit Care Med 1985; 13: 818-829.

10 Prat C, Dominguez J, Rodrigo, et al. Procalcitonin, Creactive protein and leukocyte count in children with lower respiratory tract infection. Pediatr Infect Dis J 2003; 22: 963-968.

11 Toikka $\mathrm{P}$, Irjala $\mathrm{K}$, Juven $\mathrm{T}$, et al. Serum procalcitonin, C-reactive protein and interleukin-6 for distinguishing bacterial and viral pneumonia in children. Pediatr Infect Dis J 2000; 19: 598-602.

12 Hedlund J, Hansson LO. Procalcitonin and C-reactive protein levels in community-acquired pneumonia: correlation with etiology and prognosis. Infection 2000; 28: 68-73.

13 Brunkhorst FM, Al-Nawas B, Krummenauer F, Forycki ZF, Shah PM. Procalcitonin, C-reactive protein and APACHE II score for risk evaluation in patients with severe pneumonia. Clin Microbiol Infect 2002; 8: 93-100.

14 Ssali FN, Kamya MR, Wabwire-Mangen F, et al. A prospective study of community-acquired bloodstream infections among febrile adults admitted to Mulago Hospital in Kampala, Uganda. J Acquir Immune Defic Syndr Hum Retrovirol 1998; 19: 484-489.

15 Penner C, Roberts D, Kunimoto D, Manfreda J, Long R. Tuberculosis as a primary cause of respiratory failure requiring mechanical ventilation. Am J Respir Crit Care Med 1995; 151: 867-872.

16 Barnes PF, Chattee D, Abrams JS, et al. Cytokine production induced by Mycobacterium tuberculosis 
lipoarabinomannan. Relationship to chemical structure. J Immunol 1992; 149: 541-547.

17 Rautonen J, Rautonen N, Martin NL, Philip R, Wara DW. Serum interleukin- 6 concentrations are elevated and associated with elevated tumor necrosis factor-alpha and immunoglobulin $\mathrm{G}$ and A concentrations in children with HIV infection. AIDS 1991; 5: 1319-1325.

18 Whang KT, Vath SD, Becker KL, et al. Procalcitonin and proinflammatory cytokine in interactions in sepsis. Shock 1999; 12: 268-273.

19 Al-Nawas B, Shah PM. Procalcitonin in acute malaria. Eur J Med Res 1997; 2: 206-208.

20 Christofilopoulou S, Charvalos E, Petrikkos G. Could procalcitonin be a predictive biological marker in systemic fungal infections? Study of 14 cases. Eur I Intern Med 2002; 13: 493-495.

21 Schleicher GK, Feldman C. Dual infection with Streptococcus pneumoniae and Mycobacterium tuberculosis in HIV-seropositive patients with community acquired pneumonia. Int J Tuberc Lung Dis 2003; 7: 1207-1208.

22 Casado JL, Navas E, Frutos B, et al. Salmonella lung involvement in patients with HIV infection. Chest 1997; 112: 1197-1201.

23 Christ-Crain M, Jaccard-Stolz D, Bingisser R, et al. Effect of procalcitonin-guided treatment on antibiotic use and outcome in lower respiratory tract infections: clusterrandomised, single-blinded intervention trial. Lancet 2004; 363: 600-607. 